\title{
Analysis on innovation strategy of agricultural sustainable business model - Taking Agricultural Maker Space "maker spark" in Sichuan Province as an Example
}

\author{
Yufeng Li, Ke Zheng*, and Yan Wang \\ College of Management, Sichuan Agricultural University, Chengdu, China
}

\begin{abstract}
Sustainable business model innovation is increasingly prominent in response to the increasingly urgent issue of sustainable development. It is a creative solution focusing on the long-term development of the organization. The problem of sustainable development in the agricultural field is prominent, and as the agricultural maker space, "maker spark" has become the experimental field and innovation highland of sustainable business model innovation in the agricultural field. Based on the investigation of 32 agricultural maker space operators in Sichuan Province, this paper uses the grounded research method to identify ten agricultural sustainable business model innovation strategies and put forward the concept framwork of "resource connotation mining, customer value optimization, value radiation and coordination" to describe the internal logic of achieving business sustainability, social sustainability and ecological sustainability. The paper also matches the ten sustainable business model innovation strategies with the nine common prototype strategies identified by foreign scholars. Finally, on the basis of in-depth analysis of the realistic constraints of China's agricultural development, the paper believes that the innovation of agricultural sustainable business model is a creative response to the constraints of modern agricultural development.
\end{abstract}

\section{Introduction}

In the context of the increasingly urgent problem of sustainable development, the importance of sustainable business model innovation is gradually emerging. This is a creative solution that is committed to deal with environmental, ecological, social constraints and the demands of a wide range of stakeholders, focusing on the long-term development of the organization. With the development of information technology, electronic commerce and the continuous transformation of business landscape, business model and its innovation have become the primary and core elements for the competition of organizations today.Sustainable business model innovation, as an innovation strategy and path, is guided by the diversified interests of a wide range of stakeholders and takes the long-term sustainable development of an organization as the goal to explore effective solutions to environmental, ecological, social constraints.It is considered to be of great importance in addressing the global and increasingly pressing issues of sustainable development, translating the fruits of sustainable technological development into market value, realizing the transformation of society to a sustainable economic system $^{[1][2]}$.

Under the background of digital transformation and integration of three industries, the space and freedom of business model innovation of agricultural management organizations have been greatly improved. This is of great importance to the development of modern agricultural industry, such as breaking through factor constraints, overcoming institutional barriers, improving supply quality, optimizing resource allocation, and exploring new growth points of value. China's agricultural development is facing with prominent sustainable development problems and practical constraints, such as poverty and development of the bottom people, food safety and green development, resource constraints and production efficiency improvement, institutional barriers and human resources shortage. This means that seeking for sustainable business model innovation will be the only way for the development of modern agriculture.

At present, many of the actual construction of maker spark lack legitimacy, and its construction and strategic choice are often inseparable from the development needs of the "maker spark" business entities themselves. The survey found that "maker spark" has actually become the experimental field and innovation highland for sustainable business model innovation in the agricultural field.In order to solve the problem of sustainable development, many new values have been explored, new transaction models have been constructed, new stakeholder collaboration platforms have been created, the extension of industrial chain and integration mode of the three industries have been explored continuously. This is of great significance to the innovation of agricultural industry, the increase of agricultural industry competitive advantages, the promotion of modern agricultural industry

\footnotetext{
*Corresponding author: 13828@sicau.edu.cn
} 
upgrading, and the response to the sustainable development of agriculture ${ }^{[3]}$.

To this end, this paper conducts an investigation on 32 representative operators of maker spark in Sichuan Province. This paper identifies innovative strategies of agricultural sustainability business model through grounded analysis, analyzing and interpreting them in combination with theories, so as to provide references for the direction guidance of agricultural sustainability development path.

\section{Literature review}

Sustainability issues on a global scale, such as inequality, resource shortages, and the deterioration of natural ecology, coupled with increasingly stringent regulations, make the transition to a sustainable economic system more and more necessary ${ }^{[2]}{ }^{[4]}$. Therefore, an overall plan that takes into account economic, environmental and social changes is needed to deal with the challenge of sustainability ${ }^{[4]}$. The characteristics of a sustainable economic system are: (1) Encourage the reduction of consumption and set the upper limit of resource use; (2) Maximize social and environmental benefits; (3) Closedloop system, do not allow anything to be wasted or discarded into the environment; (4) Emphasize the delivery of functions and experience instead of Product ownership; (5) Provide a substantial and meaningful work experience for everyone to enhance human creativity/skills; (6) Based on collaboration and sharing rather than active competition ${ }^{[2]}{ }^{[5]}$.Although there are more technological advances committed to sustainable development, to achieve sustainable development goals, it is necessary to adjust the incentive mechanism and profit mechanism, which means to innovate at the level of business models ${ }^{[2]}{ }^{[6]}$.Companies need to integrate value propositions, upstream and downstream value chains, and financial models to bring sustainable innovation to the market ${ }^{[7]}$.The pursuit of sustainable innovation is the source of organizational and technological innovation, leading to new supply chain design methods and business models, bringing more diversification and value creation opportunities $^{[8][9]}$.

Responding to multiple stakeholders and providing diversified values that are conducive to sustainable development are the essential characteristics of a sustainable business model. A sustainable business model is a business model that aims to "create monetary and nonmonetary value for a wide range of stakeholders and adopt a long-term perspective" ${ }^{[2]}$. It is a way to create customer and social value by integrating social, environmental and business activities ${ }^{[10]}$.It transcends economic value and provides other forms of value to a wider range of stakeholders to create balanced social, environmental and economic value ${ }^{[11]}$. The sustainable business model itself has become a source of competitive advantage ${ }^{[9]}$.Sustainable business models can be used as a tool to coordinate sustainable technology and social innovation at the system level ${ }^{[4]}$.

Business model innovation reconceptualizes the company's purpose, value creation logic, and value concepts, thereby providing a method for the changes needed to address sustainability issues, and is considered to be the key to achieving greater social and environmental sustainability in industrial systems ${ }^{[4]}$.Sustainable business model innovation combines business model innovation elements with sustainable value, and adopts solutions that promote sustainability in the value proposition, value creation and acquisition or value network of the business model, or changes the organization and the way its value network creates, delivers and obtains value, to achieve the goal of having a positive impact on the environment, society and the long-term prosperity of the organization and its stakeholders ${ }^{[2]}{ }^{[11]}$. This also means proactively bringing a wide range of stakeholders into the management category ${ }^{[12]}$.

In recent years, scholars have identified a universal sustainable business model, that is, a universal business model strategy for creating sustainable value.Such as Eight types of product-service system (PSSs) $)^{[13]}$, committed to providing bottom-level customers with simplified low-cost products and services at the bottom of the pyramid model ${ }^{[14][15]}$, circular business model ${ }^{[16]}$, social enterprise, etc ${ }^{[17]}$. Based on literature research and practical experience, Bocken et al. identified eight general sustainable business model prototypes through coding analysis ${ }^{[4]}$.Later, Ritala et al. perfected it into nine types including maximizing materials and energy efficiency on the basis of Bocken's work ${ }^{[14]}$.

\section{Research methods and research process}

The research on business model and its innovation in both theoretical and quantitative level is insufficient, and even less effective quantitative tools. This is even more so when it comes to sustainable business model.Qualitative research, as an inductive theoretical research, is an activity of obtaining an interpretive understanding of the behavior and meaning construction by interacting with the object of study.Compared with quantitative research, its advantage lies in the construction of a deep and thorough understanding and explanation of social phenomena ${ }^{[19][20]}$. Therefore, this approach will be more conducive to the exploration and analysis of the specific strategies of sustainable business model innovation and development in the unique context of China's agricultural development.This study follows the general process of grounded research, abstracts concepts and categories from the research text, and further develops the relationship between categories to form a theoretical framework.

\subsection{Source of Cases}

The cases in this paper comes from the text data from the field investigation of 32 modern Agricultural maker Space 'maker spark' project in Sichuan Province.Text sources: (1) Background information collected by the research team from the open media; (2) Audio recordings of in-depth interviews with the directors of the 32 operating entities of the agricultural maker space maker spark and their translation into text; Open-ended questions were used in 
the interview, mainly including: 'Tell me about your process of building and operating maker spark?' 'What development goals and strategies have been set?' 'What are your attempts and major innovations in your business model?' 'What was the main difficulty facing you? How was it solved?' 'What attempts have been made to address sustainability issues?', etc; (3) The information obtained from interviews and observations made by team members, each case was assigned 3-5 investigators to form an investigation team to collect centralized information and discuss, and then reached a consensus on the investigated Business model of maker spark, formed a descriptive text of the business model of maker spark. Eventually, a text of about 160,000 words was formed as the basis for coding.

\subsection{Encoding Process}

This paper conduct research according to the three phases of open coding, axial coding and selective coding, which are classified by Strauss. Open coding is the initial step of grounded theory analysis and the preliminary categorization of data. Spindle coding is to inductively connect the initial categories, so as to further the nature and dimension of categories, which is the process of reintegrating the original data that has been decomposed. Selective coding refers to selecting core categories, associating other categories and verifying relationships between them. In this study, the coding process is based on the grounded theory method, and Nvivo11 software is used as the auxiliary software to open into the original materials to make the core problems naturally appear.

\subsubsection{Open Coding}

On the basis of independent coding by each member of the research group, the original concept was modified and adjusted continuously through debating discussion to ensure the rationality of coding. The study eventually developed 208 related concepts, based on which generalizations, deletions and abstractions were made. After repeated discussion, questioning and modification, the research team finally concluded 40 categories, as shown in Table 1.

Table1. Open coding for sustainable business model innovation of maker spark.

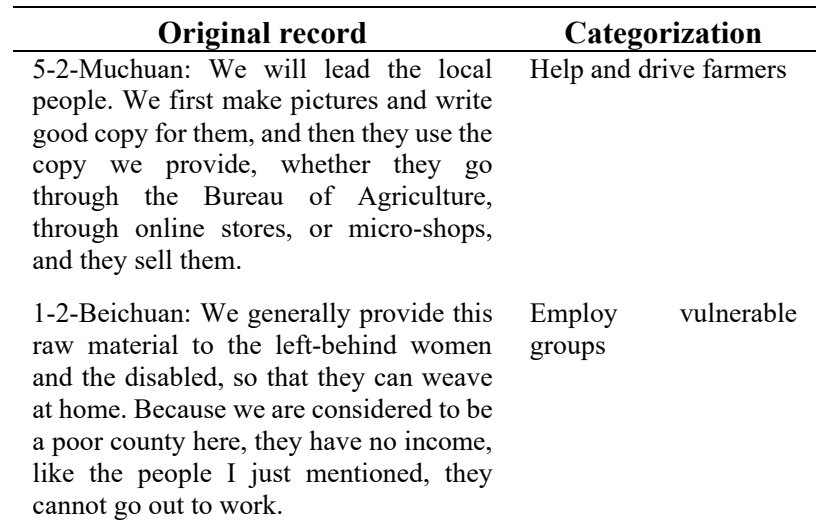

7-2-Jinsha: Labor is cheap. We are 18 to 35 years old and account for the majority. These people are unwilling to go out to work, he does not want to leave his hometown, he may not be used to going to the city.

1-4-Pengyuan: We mainly train four types of entrepreneurs, including veterans, returning migrant workers, the disabled, and poor households, as well as college students returning to their hometowns to start businesses. We are all very kind, especially for the entrepreneurship of the disabled.

2-2-Guanghan: They don't have (field), some of them are from other places.If they have a small amount of contracting from the farmers, they will not be able to contract the (land). We are all contracted out in pieces.

1-2-Beichuan: Because we have a five-Alevel scenic spot in Banaqia Commercial Street, plus a Jiuhuang Mountain and other scenic spots.

5-4-Zhubian: For Qingshen, bamboo weaving was a long time ago. Since 1984, the chairman of our company started making bamboo weaving and making some production and daily necessities with his grandfather since he was a child. Later, he became more famous.

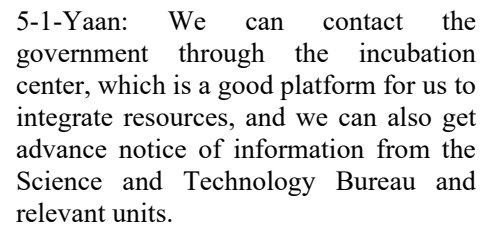
government through the incubation center, which is a good platform for us to integrate resources, and we can also get advance notice of information from the Science and Technology Bureau and relevant units.

$\begin{array}{ll}\begin{array}{l}\text { Employ } \\ \text { groups }\end{array} & \\ & \\ \text { Help } & \text { smalnerable }\end{array}$

entrepreneurs

Large-scale acquisition of land resources

Efficient use of location endowment resources

Efficient use of featured resources utilization of government resources

\subsubsection{Axial Coding}

Based on 208 concepts formed by open coding and 40 subcategories generated by induction and abstraction, we deeply analyzed the relationship among sub-categories, reorganized the split data in open coding, and established genera. Finally, 10 main categories were established, including support for the bottom group, efficient utilization of local resources, full utilization of government resources, optimization and improvement of technology, optimization of supply and demand matching, improvement of satisfaction, control of production process, expansion of value space, promotion of ecological development and incubation support. The specific category relationship is shown in Table 2 .

Table2. Axial coding for sustainable business model innovation of maker spark

\begin{tabular}{ll}
\hline \multicolumn{1}{c}{ Main categories } & \multicolumn{1}{c}{ Sub-categories } \\
\hline Support for the bottom group & $\begin{array}{l}\text { Help and drive farmers, employ } \\
\text { vulnerable groups, employ local } \\
\text { people, help small entrepreneurs }\end{array}$ \\
$\begin{array}{l}\text { Efficient utilization of local } \\
\text { resources }\end{array}$ & $\begin{array}{l}\text { Large-scale acquisition of land } \\
\text { resources, efficient use of location }\end{array}$
\end{tabular}




\begin{tabular}{|c|c|}
\hline & $\begin{array}{l}\text { endowment resources, efficient } \\
\text { use of featured resources }\end{array}$ \\
\hline $\begin{array}{l}\text { Full utilization of government } \\
\text { resources }\end{array}$ & \begin{tabular}{lrr} 
Leverage & \multicolumn{2}{c}{ government } \\
infrastructure support, leverage \\
government program support, \\
leverage government \\
support
\end{tabular} \\
\hline $\begin{array}{l}\text { Optimization and improvement } \\
\text { of technology }\end{array}$ & $\begin{array}{l}\text { Obtain external technical support, } \\
\text { technological accumulation and } \\
\text { innovation }\end{array}$ \\
\hline $\begin{array}{l}\text { Optimization of supply and } \\
\text { demand matching }\end{array}$ & $\begin{array}{l}\text { Develop e-commerce platforms, } \\
\text { open key channels }\end{array}$ \\
\hline Improvement of satisfaction & $\begin{array}{l}\text { Develop customization patterns, } \\
\text { increase experience value }\end{array}$ \\
\hline Control of production process & $\begin{array}{l}\text { Unify supply of key raw } \\
\text { materials, create a hosting model, } \\
\text { develop the circular economy }\end{array}$ \\
\hline Expansion of value space & $\begin{array}{l}\text { Expand the scale of industry, } \\
\text { develop deep processing, build a } \\
\text { mature industrial chain, develop } \\
\text { integration of the three industries, } \\
\text { estate planning }\end{array}$ \\
\hline $\begin{array}{l}\text { Promotion of ecological } \\
\text { development }\end{array}$ & $\begin{array}{l}\text { Build an innovation platform, } \\
\text { build a regional platform, help to } \\
\text { build cooperative relations with } \\
\text { others, guide internal solidarity } \\
\text { and mutual assistance, } \\
\text { demonstration drive }\end{array}$ \\
\hline Incubation support & $\begin{array}{l}\text { Strategy guide, incentives to } \\
\text { promote, establish win-win } \\
\text { mechanisms, marketing service, } \\
\text { technical support, integrated } \\
\text { management services, provide } \\
\text { training and guidance services, } \\
\text { talents conveying, physical } \\
\text { facility support, financial support, } \\
\text { connecting and utilization of } \\
\text { government resources }\end{array}$ \\
\hline
\end{tabular}

\subsubsection{Selective Coding}

Selective coding is to analyze and deal with the relationship between categories, synthesize and further explore the core categories, and then build a theoretical framework. This paper then put forward the "resource connotation mining_— customer value optimization- value radiation and synergy" conceptual framework for the representation of how the ten sustainable business model innovation strategies meet common business, social and ecological environment sustainable development demand. And we highlight the interaction between the three kinds of strategies, details are shown in figure 1 below. Thus, the sustainable business model innovation strategy of maker spark can be analyzed: (1) Resource connotation mining, including support for the bottom group, efficient utilization of local resources and full utilization of government resources three strategies, aimed at through upgrading vulnerable labor skills, creativity and development opportunities, to dig and maximize the use of resources, to protect and expand the value of the original regional resources potential, and to guide, integrate and utilize public resources provided by the government. The ultimate goal is to achieve social and ecological sustainable development and increase support for business sustainability. (2)Customer value optimization, the emphasis is promoting business sustainability, including optimization and improvement of technology, optimization of supply and demand matching, improvement of satisfaction, and control of production process four strategy. Among them, optimization of supply and demand matching, and improvement of satisfaction increase customer value and its responsiveness to customer demand. Control of production process improved the efficiency of resource utilization through Unified supply of key raw materials, created a hosting model, and developed the circular economy. It replaces the transfer of property rights with services, reduces the pollution to the environment and saves resources by building a closed resource cycle. The promotion of business sustainability lays the foundation for value radiations and synergies. (3) Value radiation and synergy, including expansion of value space, promotion of ecological development, and incubation support. The expansion of industrial value space brings positive economic externalities. To promote the synergetic symbiosis of diversified stakeholders and provide incubation support, so as to realize ecological cooperation and win-win development. 


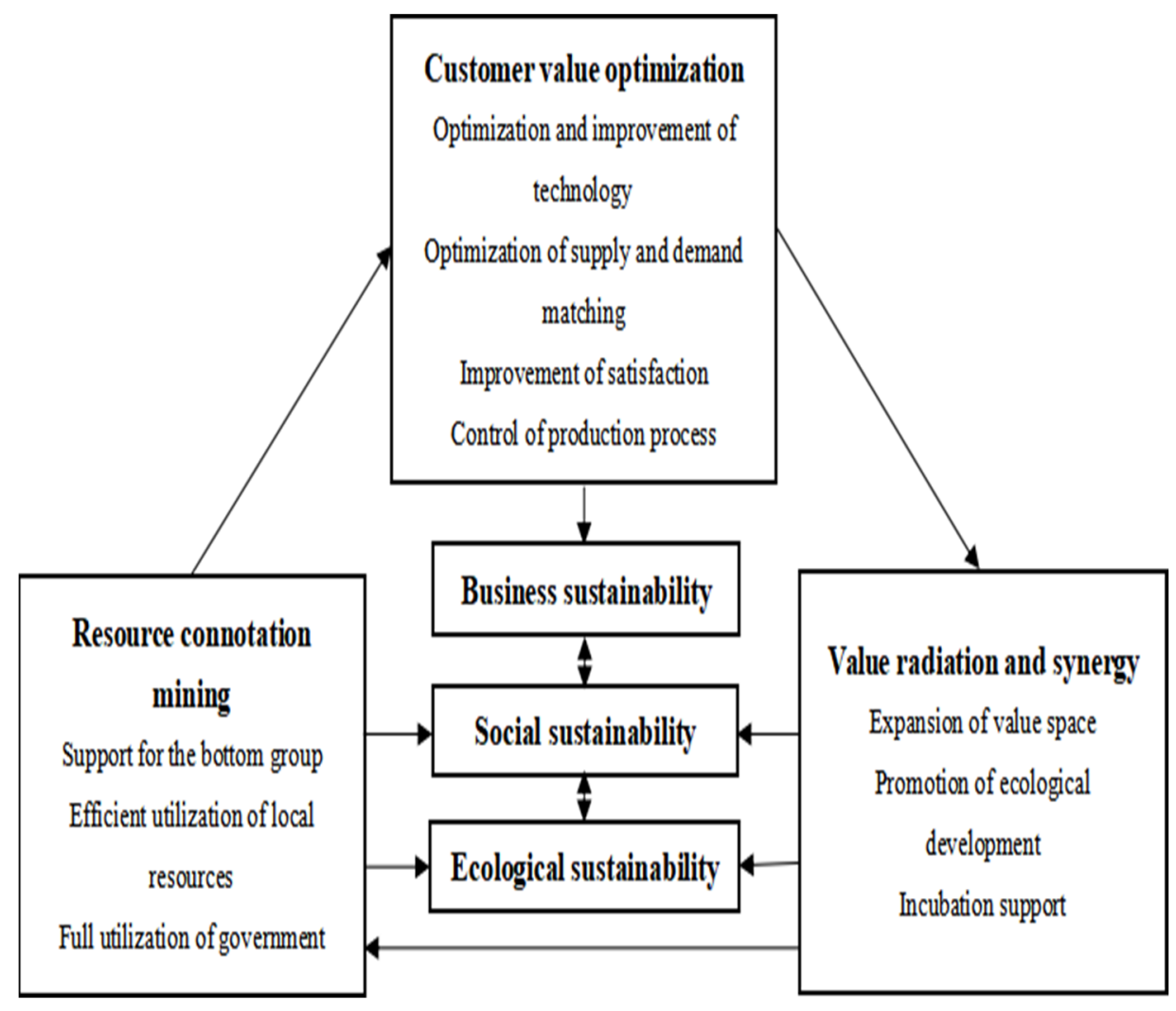

Fig1. Conceptual framework of innovative strategies for agricultural sustainability business model

\subsubsection{Saturation Test}

Saturation means that there are no new concepts, categories or relationships in the new data, and the abstracted concepts or categories in the research are enough to cover the data collected by researchers and even the new data ${ }^{[21]}$. The research team is divided into seven groups with 3-5 people as a group. Separate coding is adopted, followed by discussion and coding verification to ensure that no categories are omitted and theoretical saturation is reached.

\section{Results and discussion}

\subsection{The dimension and strategy prototype identification of Sustainable Business Model Innovation for maker spark}

Based on the nine generic sustainability business model innovation prototype strategies summarized by Bocken et al. (2014, 2016) and Ritala et al. (2018), the ten agricultural maker space sustainability business model innovation strategies identified in this paper were matched with them. The results are shown in Table 3 below. Row headers is the prototype strategy and column headers is the value link of business model innovation .The research shows that except replacement with renewable energy and natural processes and promoting adequacy two prototype strategies, other prototype strategies are reflected in the innovation strategy of The sustainable business model of maker spark.

Table3. Matching of agricultural sustainability business model innovation strategy and nine general prototype strategies

\begin{tabular}{|c|c|c|c|c|}
\hline $\begin{array}{c}\text { Generic strategy } \\
\text { prototype } \\
\text { Innovation } \\
\text { dimensions }\end{array}$ & Value proposition & Value creation & Value delivery & Value Capture \\
\hline
\end{tabular}




\begin{tabular}{|c|c|c|c|c|}
\hline $\begin{array}{c}\text { Maximize } \\
\text { material and } \\
\text { energy efficiency }\end{array}$ & & $\begin{array}{l}\text { Efficient utilization of } \\
\text { local resources-Large- } \\
\text { scale acquisition of land } \\
\text { resources, efficient use of } \\
\text { location endowment } \\
\text { resources; Control of } \\
\text { production process- } \\
\text { Unify supply of key raw } \\
\text { materials, create a hosting } \\
\text { model; Optimization } \\
\text { and improvement of } \\
\text { technology-Obtain } \\
\text { external technical support, } \\
\text { technological accumulation } \\
\text { and innovation }\end{array}$ & & \\
\hline $\begin{array}{c}\text { Closed resource } \\
\text { cycles }\end{array}$ & & $\begin{array}{l}\text { Control of production } \\
\text { process-Develop the } \\
\text { circular economy }\end{array}$ & & \\
\hline $\begin{array}{l}\text { Provide } \\
\text { functionality } \\
\text { rather than } \\
\text { ownership }\end{array}$ & & $\begin{array}{l}\text { Control of production } \\
\text { process-Create a hosting } \\
\text { model }\end{array}$ & & \\
\hline $\begin{array}{c}\text { Assume } \\
\text { management } \\
\text { responsibilities }\end{array}$ & & $\begin{array}{l}\text { Control of production } \\
\text { process-Unify supply of } \\
\text { key raw materials }\end{array}$ & & \\
\hline $\begin{array}{c}\text { Reuse for social } \\
\text { or environmental } \\
\text { purposes }\end{array}$ & $\begin{array}{l}\text { Promotion of ecological } \\
\text { development-Help to } \\
\text { build cooperative } \\
\text { relations with others, } \\
\text { guide internal solidarity } \\
\text { and mutual assistance, } \\
\text { demonstration drive }\end{array}$ & $\begin{array}{l}\text { Full utilization of } \\
\text { government-Leverage } \\
\text { government infrastructure } \\
\text { support, leverage } \\
\text { government program } \\
\text { support, leverage } \\
\text { government policy support }\end{array}$ & & $\begin{array}{l}\text { Expansion of value } \\
\text { space-Expand the } \\
\text { scale of industry, } \\
\text { develop deep } \\
\text { processing, build a } \\
\text { mature industrial } \\
\text { chain, develop } \\
\text { integration of the three } \\
\text { industries, estate } \\
\text { planning }\end{array}$ \\
\hline $\begin{array}{c}\text { Inclusive value } \\
\text { creation }\end{array}$ & $\begin{array}{l}\text { Support for the bottom } \\
\text { group-Help and drive } \\
\text { farmers, employ } \\
\text { vulnerable groups, } \\
\text { employ local people, } \\
\text { help small entrepreneurs; } \\
\text { Promotion of ecological } \\
\text { development-Build an } \\
\text { innovation platform, } \\
\text { build a regional platform }\end{array}$ & & $\begin{array}{l}\text { Optimization of } \\
\text { supply and demand } \\
\text { matching-Develop } \\
\text { e-commerce platforms }\end{array}$ & $\begin{array}{l}\text { Expansion of value } \\
\text { space-Expand the } \\
\text { scale of industry, } \\
\text { develop deep } \\
\text { processing, build a } \\
\text { mature industrial } \\
\text { chain, develop } \\
\text { integration of the three } \\
\text { industries, estate } \\
\text { planning; } \\
\text { Improvement of } \\
\text { satisfaction } \\
\text {-Develop } \\
\text { customization } \\
\text { patterns, increase } \\
\text { experience value }\end{array}$ \\
\hline $\begin{array}{c}\text { Develop } \\
\text { sustainable scale- } \\
\text { up solutions }\end{array}$ & $\begin{array}{l}\text { Promotion of ecological } \\
\text { development-Build an } \\
\text { innovation platform, } \\
\text { build a regional platform }\end{array}$ & & & $\begin{array}{l}\text { Incubation support- } \\
\text { incentives to promote, } \\
\text { establish win-win } \\
\text { mechanisms }\end{array}$ \\
\hline
\end{tabular}

\subsection{The innovation of sustainable business model of maker spark is a creative response to the constrained situation}

The field survey found that the sustainable business model innovation of maker spark is essentially the result of creatively seeking sustainable solutions under the realistic constraints of modern agricultural development.
Specifically, through interviews and operator interviews, seven major constraints were identified:

1) Significantly affected by location endowment resources: Unlike industry and service industries, agricultural production is more dependent on natural location conditions. Through research, it is found that the construction, planning and operation of many maker spark rely on unique climate and geographical conditions, as well as unique location endowment resources. Characteristic traditional resources such as traditional 
crafts and unique culture are also used to build brand value. Some high-end varieties are only suitable for growth in specific climate and geographical conditions, while some branded agricultural products have to rely on traditional crafts or culture to generate added value. Therefore, the builders of maker spark often attach great importance to the development and utilization of location endowment resources.

2) Subject to the institutional constraints of the use of land elements : China's unique land property rights institutional arrangements have a significant impact on the acquisition and use of the most important land element in agricultural production and management. The essence of contracting right is membership right, which is nontransferable and depends on membership.The management right can be transferred, but an efficient land transfer market has not been formed so far. The farmers' willingness to transfer land is low, and the transfer time is restricted by the contract right, and long-term transfer is often difficult.This means that the current transaction costs of cultivated land resources are relatively high, the risks of long-term investment are relatively high, and the costs are relatively high. The attitude and behavior of the government often have a key impact.

3) Significantly restricted by the lack of human capital: Although new farmers with new thinking, new ideas, new marketing, new organizations, and new knowledge are emerging, the main operating entities and a large number of hatched entities of maker spark are typical new farmers. However, in general, the lack of human capital, especially high-end human capital with modern agricultural production skills, entrepreneurial talents, and social entrepreneurial intentions, is still a key factor restricting the development of maker spark. On the one hand, the current composition of small farmers is biased towards the aging population, with a higher proportion of vulnerable groups such as women and the disabled; on the other hand, in the development of modern agricultural marketization, the most critical links are technical and market links. In fact, many maker spark is committed to innovation in marketing and technology applications, but the lack of marketing and management talents often becomes a bottleneck for their development.

4) Need to respond to the demands of small farmers to connect with modern agriculture: At present, small-scale production units still occupy an important proportion of agricultural production. In the process of developing modern agriculture, it is necessary to consider the reconstruction of these traditional relatively backward production units through the interest linkage mechanism, and incorporate the innovation of related business models into the modern in the agricultural production system. The survey found that helping and driving farmers, helping weak and small entrepreneurs, providing training and guidance services, and driving demonstrations are important content for the incubation and cultivation of modern agricultural production entities by maker spark.

5) Affected by the characteristics of agricultural technology supply: Agricultural technology is one of the most important modern agricultural production factors and an essential means to transform traditional agriculture.
Agricultural technology has strong regionality, long research and development cycle, poor confidentiality, and high risk of adoption. It is difficult to rely on market regulation and has the attributes of a public product. Agricultural technology has strong regionality, long research and development cycle, poor confidentiality, and high risk of adoption. It is difficult to rely on market regulation and has the attributes of a public product. In China, the developers of agricultural technology are scientific research institutes and other public institutions, and the extension function is undertaken by the agricultural technology extension service system composed mainly of science and technology commissioners and expert courtyards. maker spark itself is also the inheritance, innovation and development of the "Spark Plan" promoted by the government to promote rural economic development through science and technology in the new era.maker spark often undertakes the functions of transformation of scientific research results, technology promotion, technology demonstration, and technical training. It often has important cooperation or personal relationships with scientific research institutes or technical experts ${ }^{[22]}$.

6) Constrained by the characteristics of the agricultural industry and the market: Agriculture is a lowquality industry with low entry barriers but high risks, long production cycles and low demand elasticity, small differences in agricultural products and low recognition, difficult brand building, and greatly affected by market price fluctuations and changes in consumer preferences. The small-scale production unit-based or basic production model is difficult to achieve economies of scale, and the processing value-added rate is low. The entry of industrial and commercial capital is subject to current policy restrictions and institutional norms. The survey found that breaking down institutional barriers, promoting innovation on the sales side including sales models and sales channels, developing brand agriculture, and implementing innovations in the integration of the tertiary industries to increase added value are exactly the functions that many maker spark are committed to managing.

7) Significantly affected by the attitude and behavior of the government: Agriculture is a civilian production industry, and the government's policy support system is an important supporting force for agricultural development. Field research found that relevant government functional departments actually have many functions such as identification, evaluation, screening, recommendation, support, investment, etc. The government plays a vital role in certain aspects of the function of maker spark. Sometimes, the government, in a sense, is even a "coentrepreneur" of maker spark, jointly planning for resource use and development models. While giving full play to the advantages of the government's resources, it has also led to the "parasitic" of the government by maker spark, which lacks endogenous growth momentum and not conducive to the survival of the fittest. The managers of maker spark reflect the characteristics of high sensitivity to the attitude and behavior of the government and excessive dependence on government resources. maker spark needs to play its incubation function under many constraints to build an innovation and 
entrepreneurship ecosystem. The sustainable business model innovation of maker spark is a creative response to the constraint situation. Figure 2 can illustrate the matching logic of constraint conditions and sustainable business model innovation strategies.

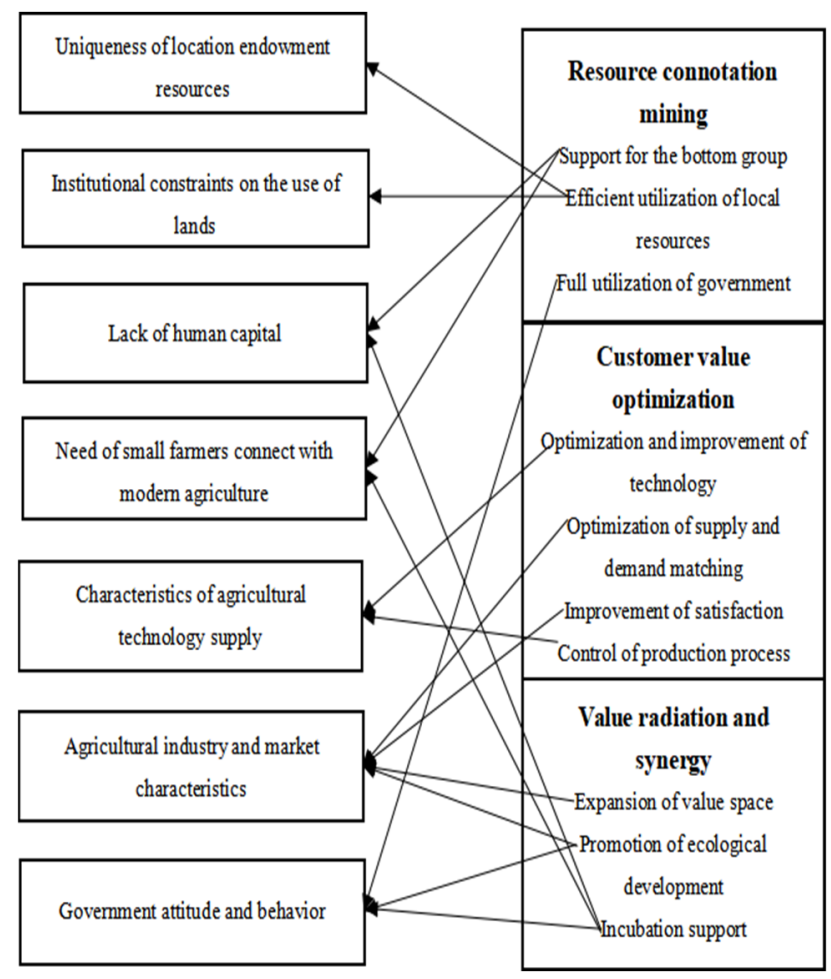

Fig2. The matching of constraints and sustainable business model innovation strategies

\section{Conclusion}

Under the rigorous reality of the issue of sustainable agricultural development, this article has practical significance for the study of innovative strategies for agricultural sustainable business models. After visiting and investigating 32 maker spark in Sichuan Province, using grounded research methods, we identified ten innovative strategies for sustainable agricultural business models. The strategies are classified, and the conceptual model of "resource connotation mining_customer value optimization_-value radiation and synergy" is proposed to describe the internal logic of achieving commercial sustainability, social sustainability and ecological sustainability. Our research can not only promote the theoretical research of sustainable agricultural business model innovation, but also provide reference for the direction of agricultural sustainable development.

\section{Acknowledgment}

This work was supported by Sichuan Science and Technology program (2019JDR0037).

\section{References}

1. Rashid, A. , Asif, F. M. A. , Krajnik, P. , \& Nicolescu, C. M. . (2013). Resource conservative manufacturing: an essential change in business and technology paradigm for sustainable manufacturing. Journal of Cleaner Production, 57(oct.15), 166-177.

2. Geissdoerfer, M. , Vladimirova, D. , \& Evans, S. . (2018). Sustainable business model innovation: a review. Journal of Cleaner Production, 198(PT.11652), 401-416.

3. Ministry of Science and Technology of the People's Republic of China. (2016). Notice of the Ministry of Science and Technology on the announcement of the first batch of maker spark List. www.most.gov.cn/fggw/zfwj/zfwj2016/201612/t201 61207_129418.htm

4. Bocken, N. M. P. , Short, S. W. , Rana, P. , \& Evans, S. . (2014). A literature and practice review to develop sustainable business model archetypes. Journal of Cleaner Production, 65(FEB.15), 42-56.

5. Jackson, T. . (2009). Prosperity without Growth: Economics for a Finite Planet. London:Earthscan Publications Ltd.

6. Rashid, A. , Asif, F. M. A. , Krajnik, P. , \& Nicolescu, C. M. . (2013). Resource conservative manufacturing: an essential change in business and technology paradigm for sustainable manufacturing. Journal of Cleaner Production, 57(oct.15), 166-177.

7. Boons, F. , \& Luedeke-Freund, F. . (2013). Business models for sustainable innovation: state of the art and steps towards a research agenda. Journal of Cleaner Production, 45(apr.), 9-19.

8. Nidumolu, R., Prahalad, C. K. , \& Rangaswami, M. R. . (2009). Why sustainability is now the key driver of innovation. International Trade Forum, 43(2), 8591.

9. Porter, M. E. , \& Kramer, M. R. . (2011). The big idea: creating shared value. how to reinvent capitalismand unleash a wave of innovation and growth. Harvard Business Review, 89(1-2), 62-77.

10. Schaltegger, S. , Florian Lüdeke-Freund, \& Hansen, E. G. . (2012). Business cases for sustainability and the role of business model innovation: developing a conceptual framework. International Journal of Innovation \& Sustainable Development, 6(2), 95-119.

11. Bocken, N., Short, S., Rana, P., \& Evans, S. . (2013). A value mapping tool for sustainable business modelling. Corporate Governance International Journal of Business in Society, 13(5), 482-497.

12. Geissdoerfer, M. , Bocken, N. M. P. , \& Hultink, E. J. . (2016). Design thinking to enhance the sustainable business modelling process - a workshop based on a value mapping process. Journal of Cleaner Production, 135(Complete), 1218-1232.

13. Tukker, A. . (2004). Eight types of product-service system: eight ways to sustainability? experiences from suspronet. Business Strategy and the Environment, 13, 246-260. 
14. Prahalad, C. K. , \& Hart, S. L. . (2002). The fortune at the bottom of the pyramid. Strategy Business, 26(1):54-67.

15. George, G. , Mcgahan, A. M. , \& Prabhu, J. . (2012). Innovation for inclusive growth: towards a theoretical framework and a research agenda. Journal of Management Studies, 49(4), 661-683.

16. Nancy, M., P., Bocken, Ingrid, \& de, et al. (2016). Product design and business model strategies for a circular economy. Journal of Industrial and Production Engineering, 33(5), 308-320.

17. Defourny, J. , \& Nyssens, M. . (2010). Conceptions of social enterprise and social entrepreneurship in europe and the united states: convergences and divergences. Journal of Social Entrepreneurship, 1(1), 32-53.

18. Ritala, P., Huotari, P., Bocken, N., Albareda, L., \& Puumalainen, K. . (2018). Sustainable business model adoption among S\&P500firms: a longitudinal content analysis study. Clean. Prod, 170, 216-226.

19. Chen, X. M.. (2000). From one to all: the generalizability of qualitative research. Educational research and experiment, 000(002), 1-7.

20. Niu, M. L.. (2006). Qualitative Research Methods in the Perspective of Public Administration. Journal of Sun Yatsen University Social Science Edition, 46(003), 76-79.

21. Jia, X. D., \& Tan, X. H.. (2010). The actual value of the classic grounded theory and its spirit to China management research. Chinese Journal of Management, 7(5), 656.

22. Du, J., Song, L. D., \& Yu, J. H. (2019). Research on the construction mode and development mechanism of Hunan maker spark. China rural science \& technology, 06-019. 